\title{
Perancangan Pembuatan Kemasan dan Labeling Home Industri Olahan Jagung Usaha Kelompok Desa Tonasa Kabupaten Takalar
}

\author{
${ }^{1}$ Nur Ihwan Safutra, ${ }^{2}$ Yan Herdianzah, ${ }^{3}$ Nurhayati Rauf, ${ }^{4}$ Anis Saleh, ${ }^{5}$ A.Dwi Wahyuni $\mathbf{P}$, \\ ${ }^{6}$ Arfandi Ahmad, 7 Muhammad Fachry Hafid \\ 1,2,3,4,5,6,7Fakultas Teknologi Industri, Universitas muslim Indonesia \\ Korespondensi: yan.herdianzah@umi.ac.id
}

\begin{abstract}
Processed Corn Business so far is very promising for those who cultivate it. If you look at the competitors who are engaged in the same business, there are already quite a lot. With better taste innovations, beautiful and attractive sizes, economical prices, and most importantly healthy and hygienic by providing attractive packaging and labels so that partner products are able to compete and sell well in the market. With the Processed Corn business (corn lunkhead, corn chips, popcorn, etc.) Home Processed Corn Industry Business Group Tonasa Village, Sanrobone District, Takalar Regency which already has regular customers will increase its marketing by making attractive packaging and labels to find markets and even agents who want to sell it, so there will be many who help to develop this corn processing business. The problems faced are (1) not yet given good packaging for processed corn products that are marketed and (2) not yet given labeling to introduce their products.

Keywords : Process Design, Manufacturing of Packaging and Labeling, Entrepreneur.

Abstrak: Bisnis Olahan Jagung selama ini sangat menjanjikan bagi yang menggelutinya. Jika melihat kompetitorkompetitor yang bergerak dibidang usaha yang sama, memang sudah cukup banyak. Dengan inovasi rasa yang lebih enak, ukuran yang cantik dan menarik, harga yang ekonomis, dan yang paling penting sehat dan higienis dengan memberikan kemasan dan label yang menarik juga sehingga produk yang mitra miliki mampu bersaing dan laku dipasaran. Dengan usaha Olahan jagung (dodol jagung, keripik jagung, popcorn, DII) Home Industri Olahan Jagung Kelompok Usaha Desa Tonasa, Kecamatan Sanrobone, Kabupaten Takalar yang sudah memiliki pelanggan tetap maka akan menambah pemasarannya dengan membuat kemasan dan label yang menarik untuk mencari pasar dan bahkan agen yang mau menjualnya, sehingga akan ada banyak yang membantu untuk mengembangkan usaha olahan jagung ini. Permasalahan yang dihadapi adalah (1) belum diberikan kemasan yang baik pada produk olahan jagung yang dipasarkan dan (2) belum diberikan labelling untuk mengenalkan produknya.
\end{abstract}

Kata Kunci : Proses Perancangan, Pembuatan Kemasan dan Labeling, Wirausaha.

\section{PENDAHULUAN}

Komoditas tanaman pangan yang strategis dan merupakan komoditas Sulawesi, terutama Sulawesi Selatan dan salah satunya adalah jagung. Jagung merupakan komoditi palawija strategis Indonesia ditinjau dari aspek pengusahaan dan penggunaan hasilnya. Permintaan jagung di dalam negeri cenderung menunjukkan peningkatan seiring dengan semakin meningkatnya permintaan jagung untuk kebutuhan bahan pangan, pakan ternak dan bahan baku industri ${ }^{1}$. Produksi jagung Indonesia memperlihatkan trend kenaikan dari tahun 2017 mencapai 5.533.169 ton namun pada tahun 2018 meningkat menjadi 5.734.326. Untuk Sulawesi Selatan pada tahun 2017 mencapai 411.993 ton namun pada tahun 2018 meningkat menjadi 420.984 ton. Khusnya Kabupaten Takalar pada tahun 2017 memproduksi jagung sebanyak 60.790 ton dan pada tahun 2018 menurun menjadi 58.470 ton dan ini menandakan bahwa perlu adanya peningkatan produksi jagung disetiap tahunnya khusnya Kabupaten Takalar².

Takalar menunjukkan bahwa terjadi fluktuasi perubahan luas area tanam. Jenis jagung yang dibudidayakan oleh petani di Kabupaten Takalar menurut data sekunder yang diperoleh dari Laporan Luas Tanam Padi Badan Ketahanan Pangan Dan Pelaksana Penyuluhan (BKP3) Tahun Anggaran 2011 dapat dilihat pada Tabel 2, yaitu Hibrida, Composit, Lokal dan Jagung Manis. Di kecamatan Pattallassang ada dua macam jenis jagung dibudidayakan yaitu jagung Hibrida dan Dari data luas tanam jagung Lokal

This is an open-access article under the CC BY 4.0 International License (c) Idea Pengabdian Masyarakat (2022)

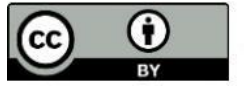
OPEN ACCESS 
yang luas keseluruhannya berjumlah 517,60 Ha. Jumlah jagung Hibrida yaitu 481,60 Ha, sedangkan untuk jagung Lokal yautu $36,60 / \mathrm{Ha}^{3}$.

Industri olahan jagung pada kelompok Usaha Desa Tonasa Kecamatan Sanrobone Kabupaten Takalar yang telah mendirikan usaha, dimana pada saat mendirikan usahanya pertama kali yaitu masih dodol jagung dan saat ini sudah berkembang usahanya dengan berbagai jenis yaitu dodol jagung, keripik jagung dan popcorn. Olahan jagung selama ini sangat menjanjikan bagi yang menggelutinya, karena olahan jagung jenis ini merupakan camilan yang enak dan mengenyangkan ${ }^{4}$.

Sistem yang mengatur proses produksi, manajemen usaha dan pemasaran agar usaha benarbenar berjalan lancar dan sesuai dengan mekanisme yang diinginkan maka manajemen usaha, maupun pemasarannya harus di dukung dengan pembuatan kemasan dan labeling ${ }^{5}$. Dengan demikian akan mudah di dalam menerapkannya manajemen usaha sehingga berjalan lancar, rapi dan sukses meskipun usaha tersebut semula kecil, memperbanyak variasi bentuk, jenis dan rasa olahan jagung yang produksi sehingga konsumen akan memiliki banyak pilihan 6 . Sedangkan model kemasan diusahakan serapi, sebersih dan semenarik mungkin, kemasan juga sangat mempengauruhi minat konsumen karena penampilan produk yang menarik dan higienis, bentuk kemasan olahan jagung basah atau kering, mahal atau murah, pengusaha harus pandai mengemasnya dan sekaligus mengenalkan produk yang dipasarkan melalui labelling?.

Usaha olahan jagung (dodol jagung, keripik jagung dan popcorn) yang sudah memiliki pelanggan tetap, maka akan menambah pemasarannya dengan membuat kemasan dan label yang menarik untuk mencari pasar dan bahkan agen yang mau menjualnya, sehingga akan ada banyak yang membantu untuk mengembangkan kelompok usaha olahan jagung ini ${ }^{8}$. Oleh karena itu perlu adanya pendampingan dan pelatihan sebagai bentuk Pengabdian Kepada Masyarakat.

\section{METODE PELAKSANAAN}

Bagian I: Tempat dan Waktu Kegiatan

Program pengabdian pada masyarakat ini dilaksanakan di Desa Tonasa kecamatan Sanrobone, Kabupaten Takalar. Praktek pelatihan dan pendampingan untuk melakukan perbaikan manajemen wirausaha, mengenalkan bagaimana cara membuat kemasan yang baik dan menarik pembuatan produk olahan jagung menjadi keripik, dodol dan popcorn dilakukan di kantor Desa Tonasa. Sedangkan waktu program kegiatan pengabdian ini dilakukan selama 1 bulan dan melakukan pelatihan secara luring.

\section{Bagian II: Peserta Pelatihan}

Peserta pelatihan adalah kelompok kelompok usaha olahan jagung yang berdomisili di desa Tonasa Kecamatan Sandrobone Kabupaten Takalar.

Bagian III: Pelaksanaan Kegiatan

Kegiatan pengabdian ini dilakukan dengan cara offline:

1. Survei lokasi kegiatan

Survei dilakukan dengan tujuan untuk menentukan tempat yang tepat dalam melaksanakan kegiatan pengabdian ini. Survei kegiatan yang dilakukan mencakup pemilihan sentra produksi jagung serta lokasi dimana akan dilaksanakannya kegiatan (pemilihan tempat yang mudah dijangkau). Negosiasi dengan Desa Tonasa sebagai mitra dalam pelaksanaan kegiatan PKM dengan tujuan untuk menentukan jadwal, tempat, dan persepsi yang sama tentang kegiatan.

This is an open-access article under the CC BY 4.0 International License (C) Idea Pengabdian Masyarakat (2022)

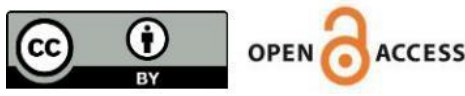


2. Survei bahan kelompok usaha bertujuan untuk memastikan olahan jagung yang sudah ada. Hal ini dipandang perlu oleh tim karena, Desa Tonasa mayoritas petani jagung, sehingga tim perlu memastikan mempersiapkan bahan siap pakai dan alat yang akan digunakan dan diberikan oleh kelompok usaha.

3. Pendemonstrasian Pelatihan bertujuan Kegiatan pengabdian kepada masyarakat ini mendemonstrasikan cara penggunaan alat-alat yang digunakan dan penyerahan modul cara pengolahan bagi kelompok warga setempat. Hal ini bertujuan agar masyarakat dapat memahami cara pengoperasian dan perawatan alat tersebut

4. Memberikan materi pengetahuan dan membuka wawasan kepada mitra tentang manajemen wirausaha sampai dengan pentingnya kemasan dan labeling pada produk olahan jagung sehingga terciptanya produk yang higienis.

5. Pelatihan manajemen usaha sampai dengan kemasan dan labeling melalui materi dan diskusi dengan mitra serta pendampingan sampai dengan pembuatan kemasan dan labeling yang dimana merupakan unsur dari pembuatan kemasan dan label yang mneunjang pemasaran produk olahan jagung sedangkan Tim Pengabdian Kepada Masyarakat dengan pendanaan Universitas Muslim Indonesia.

\section{HASIL DAN PEMBAHASAN}

Kegiatan pengabdian masyarakat dilaksanakan pada usaha kecil pembuatan produk olahan jagung pada pelaku usaha olahan jagung yang berlokasi di Desa Tonasa Kabupaten Takalar. Tim pengabdian terdiri dari ketua dan anggota dan dibantu 2 orang mahasiswa yang ikut terlibat pada kegiatan Pengabdian Masyarakat. Pada tanggal 25 November 2021 bertempat di Rumah $\mathrm{Bu}$ Arif pemilik usaha olahan jagung asli desa Tonasa Kabupaten Takalar dilaksanakan Focus Group Discussion (FGD). Berdasarkan hasil Forum Group Discussion ditetapkan beberapa permasalahan yang menjadi fokus pelaksanaan pada kegiatan pengabdian masyarakat ini, yaitu:

1. Permasalahan kemasan produk dan label produk yang kurang menarik.

2. Permasalahan dalam penentuan biaya produksi.

Beberapa hasil kegiatan yang telah dilakukan oleh Tim Pengabdian Masyarakat bersama mitra usaha sebagai berikut:

A. Pembuatan desain kemasan dan label merek produk

Pada kegiatan ini dilakukan secara bersama antara tim pengabdian masyarakat dengan mitra usaha dalam hal ini pengusaha oalahan jagung, yang mana dalam pelaksanaan kegiatan dilakukan melalui forum komunikasi 2 (dua) arah sehingga akan terjadi hubungan timbal balik pada kedua belah pihak. Memberikan wacana dan penjelasan kepada home industri produk olahan jagung selaku mitra dalam pengabdian ini bagaimana cara meningkatkan manajemen wirausaha melalui usaha yang sudah di tekuni selama ini, yaitu mengenai;

1. Kualitas produk,bagaimana membuat produk yang berkualitas, salah satu nya melalui tampilan kemasan yang cantik sehingga mampu menarik minat masyarakat.

2. Pembuatan kemasan yang menarik serta membantu membuat design labelling pada kemasan produk olahan jagung. Bagaimana membantu mitra kami dalam hal ini mitra home industri kelompok usaha oalahan jagung di desa Tonasa Kabupaten Takalar dalam membuat kemasan yang menarik, maka kami memberikan bantuan peralatan berupa mesin Hand Sealer/ Impulse Sealer sebanyak 2 unit (besar dan kecil). Mesin ini digunakan untuk merekatkan plastik pada sisinya sehingga kemasan bisa tertutup rapat. Dengan bantuan peralatan tersebut diharapkan bisa mengefisienkan waktu dan membuat tampilan kemasan lebih rapi. Sebelumnya home industri olahan jagung selaku mitra hanya menggunakan staples biasa untuk merekatkan kemasan. 

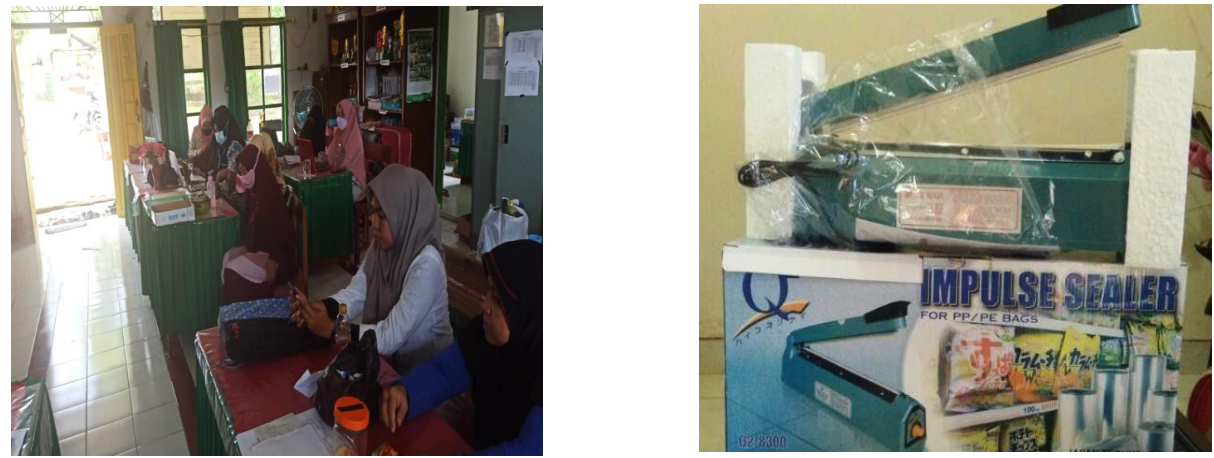

Gambar 1 \& 2. Pelatihan Packaging dan Labeling dengan bantuan alat impulse sealer

B. Pelatihan Perhitungan Harga Pokok Produksi dan Laporan Keuangan. Adapun tujuan dan dilaksanakannya kegiatan tersebut adalah memberikan pengarahan dan masukkan kepada mitra tentang cara perhitungan biaya produksi. Pertama- tama mitra diminta untuk menyebutkan biaya-biaya apa saja yang mereka keluarkan dalam memproduksi produk olahan jagung, ternyata ada biaya-biaya yang belum diperhitungkan, salah satunya adalah biaya packaging labeling yang memenuhi standar kemanan pangan olahan jagung dan tenaga kerja khususnya untuk tenaga mereka sendiri tidak diperhitungkan dan disarankan untuk memperhitungkan biaya tenaga kerja dalam menetapkan biaya produksi. Selama ini pihak mitra belum memiliki laporan keuangan, disini tim pengabdian masyarakat menyatakan betapa pentingnya memiliki laporan keuangan supaya pengusaha dapat mengetahui posisi keuangannya. Selama ini tidak ada pemisahan antara uang hasil usaha dengan keperluan pribadi, yang mana sewaktu-waktu dapat mengambil uang hasil usaha untuk keperluan pribadi/keluarga dan juga digunakan untuk usaha sehingga pada saat memerlukan dana untuk usaha akan kekurangan modal. Oleh karena itu, disarankan untuk melakukan penyisihan anggaran untuk pembelian alat-alat pendukung biaya produksi dan lain-lain. Misalnya pembelian alat pengolahan yang baik dan mudah dibersihkan harus diperkirakan usia pakai sehingga dapat diketahui waktu melakukan pembelian kembali, sehingga pendapatan yang diperoleh harus disisihkan untuk keperluan pembelian ember. Hal ini dilakukan bertujuan agar pada saat ingin membeli alat pengolahan baru sudah tersedia dana sehingga tidak akan menghambat kegiatan proses pembuatan produk olahan jagung.

Tabel 1. Uraian Pencapaian Kegiatan Pelatihan Packaging dan Labeling

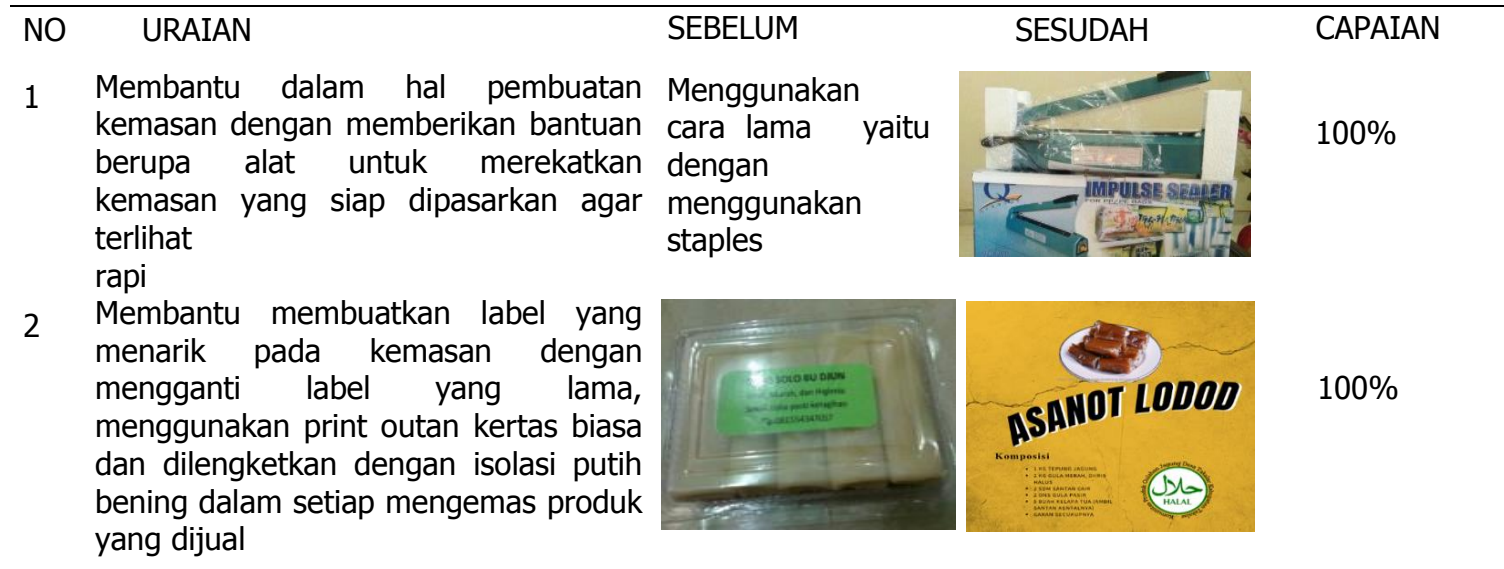

This is an open-access article under the CC BY 4.0 International License (C) Idea Pengabdian Masyarakat (2022)

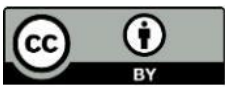




\section{KESIMPULAN}

Kegiatan pengabdian yang sudah dilakukan berupa manajemen wirausaha yang meliputi promosi dan pemasaran serta pentingnya kemasan dan labeling pada produk olahan jagung. Dimana dalam pengabdian ini kami membantu mitra ( pemilik home industri olahan jagung ) untuk masalah kemasan dengan memberikan bantuan berupa alat untuk merekatkan kemasan, yakni berupa 2 unit impulse sealer (Ukuran besar dan Ukuran Kecil) serta membuatkan label baru yang menarik untuk di letakkan pada kemasan yang akan di pasarkan serta memasang banner kecil di depan rumah Mitra ( home industri olahan jagung ) sebagai sarana promosi. Di harapkan dengan kegiatan pengabdian yang timi lakukan ini dapat menambah jumlah pelanggan/konsumen dari mitra kami ( home industri olahan jagung ).

\section{UCAPAN TERIMAKASIH}

Terimakasih kami ucapkan kepada kelompok usaha olahan jagung di Desa Tonasa, Kecamatan Sanrobone, Kabupaten Takalar yang terlibat pada pengabdian masyarakat ini.

\section{DAFTAR PUSTAKA}

1. Agato \& Narsih. 2011. Pengembangan hasil pertanian (jagung) menjadi produk susu jagung dan kerupuk jagung. Jurnal Teknologi Pangan, Vol. 2, No. 1, pp. 86-94.

2. Agustina, W. 2009. Desain Kemasan dan Label Produk Makanan. Kumpulan Modul Pelatihan. UPT B2PTTG-LIPI Subang.

3. Badan Pusat Statistik dan Direktorat Jenderal Tanaman Pangan (2018). Sulawesi Selatan.

4. Raliby et al., 2010. Perancangan Alat Pengering Kerupuk Dengan Memanfaatkan GAs Buang Dari Proses Produksi pada Industri Pembuatan Kerupuk; Prosiding Seminar Nasional Sains dan Teknologi 2010, Fakultas Teknik Universitas Wahid Hasyim Semarang.

5. Shim, A, \& Terence. 2003. Periklanan Promosi, Aspek Tambahan Komunikasi Pemasaran Terpadu, Jakarta, Penerbit Erlangga.

6. Suparmi, 2013. IbM Kalurahan Penggaron Lor Melalui Pemberdayaan PKK Dalam Pembuatan Jajanan Sehat Dengan Pewarna Alami, Semarang.

7. Triyono, A. 2002. Modul Pengemasan Produk Makanan, Kumpulan Modul Pelatihan UPT B2PTTG-LIPI Subang.

8. Widiyanti, N. M. N. Z., Baga, L. M. \& Suwarsinah, H. K. 2016. Kinerja usahatani dan motivasi petani dalam penerapan inovasi varietas jagung hibrida padalahan kering di Kabupaten Lombok Timur. Jurnal Penyuluhan, Vol. 12, No. 1, pp. 31-42. 